\title{
Sobrevivir, resistir y luchar. Las comunistas durante la década de los 80 , en Chile
}

\author{
Javiera Robles Recabarren \\ Universidad Nacional de La Plata, Argentina \\ libertad.recabarren@gmail.com \\ ORCID: 0000-0001-7132-3286
}

Titulo: Survive, resist and fight. Women communists during the eighties, Chile

Resumen: En el presente artículo se propone abordar la contribución de las mujeres comunistas durante el período de la "Política de rebelión popular de masas" del Partido Comunista de Chile. Atendiendo a la ausencia historiografica sobre el estudio de las mujeres comunistas en Chile, serán analizadas fuentes orales de antiguas militantes del partido y su brazo armado, el Frente Patriótico Manuel Rodríguez, como también de los organismos de derechos humanos, sindicatos y organizaciones populares.

Palabras claves: historia oral - género - militancia comunista

\begin{abstract}
In this paper I going to reflect about the contribution of the oral history and the gender perspective by the study of the militancy communist history in Chile for the policy of Mass Popular Rebellion of the Communist Party. Attending to the historiography absence about the study of the women communist in Chile, will be analyzed the oral source of the women was member of the communist party and its armed arms, the Frente Patriótico Manuel Rodriguez, as well as the participation of communist women in human rights organizations, trade unions and other organizations.
\end{abstract}

Keywords: oral history - gender - communist militancy

Recepción: 1 de julio de 2021. Aceptación: 14 de agosto de 2021

DOI: https://doi.org/10.46688/ahmoi.n19.330

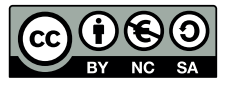

Obra bajo licencia Creative Commons 4.0 International (Atribución - NoComercial - Compartirlgual) 


\section{$* * *$}

\section{Introducción}

El Partido Comunista de Chile (PCCh) constituyó una de las fuerzas políticas de mayor importancia en el escenario político y social del país durante el siglo XX. Su origen obrero en las oficinas salitreras, su presencia en el mundo popular y la temprana decisión de disputar cargos de representación politica hicieron del PCCh un actor gravitante en los cambios sociales, proceso culminado con el triunfo de la Unidad Popular (UP). En consecuencia, la ruptura institucional provocada por el golpe de Estado del 11 de septiembre de 1973 y los diecisiete años que se prolongó la dictadura tuvieron consecuencias muy profundas en la militancia comunista y en su proyecto político, lo que provocó un proceso de reflexión interna sobre las estrategias para recuperar la democracia.

El artículo presentado a continuación se inscribe en un largo proceso de reflexión e investigación sobre las militancias comunistas en un período específico de la dictadura chilena y la historia del PCCh, el período de la "Política de rebelión popular de masas" (PRPM). ${ }^{1}$ Fue en septiembre de 1980 cuando el Secretario General del PCCh, Luis Corvalán, anunció, en un discurso en Moscú por el X aniversario de la UP (1982), la PRPM que validó todas las formas de lucha, incluida la armada. Un prolongado debate de tres años precedió a este anuncio, que marcó un antes y un después en la historia del partido. Tras esta oficialización, el Equipo de Dirección Interior del PCCh articuló el Frente Cero, estructura que concretaria la PRPM, realizando entre 1980 y 1983 acciones audaces de mediana envergadura, a cargo de equipos operativos formados militarmente en el país (Bravo, 2017). No fue hasta diciembre de 1983 cuando la orgánica militar, el brazo armado del partido, pasó a llamarse Frente Patriótico Manuel Rodríguez (Robles y Vidaurrazaga, 2021, p. 16).

En este complejo escenario también se inscribe la historia de las mujeres que se abocaron a la militancia comunista durante la década de los 80. La irrupción de la protesta en las calles controladas por la fuerza militar, los apagones en las poblaciones de las ciudades, el fuego de la barricada y la denuncia pública de las violaciones a los derechos

1. Este artículo es resultado de la tesis "Violencia política y género. Estudio de la militancia de mujeres comunistas durante el período de la Política de Rebelión Popular de Masas (1980-1990)", con la que obtuve el grado de magister en Historia y Memoria por la Universidad Nacional de La Plata en 2019. Así como también de las reflexiones a partir de la escritura de la tesis "Mujeres comunistas: entre la política armada, las ollas comunes y la defensa de los derechos humanos (Chile, 1978-1990)" para el grado de doctora en Historia por la Universidad Nacional de La Plata. 
humanos perpetradas por la dictadura fueron todas expresiones de la aceleración del tiempo histórico que se comenzó a vivir durante los 80 . En ese contexto, junto con el desmantelamiento del modelo de desarrollo chileno y de la instalación del marco institucional para uno nuevo, las mujeres comenzaron a tejer nuevamente los lazos que les permitirian no sólo sobrevivir, sino también enfrentarse a la dictadura mediante todas las formas de lucha reconocidas como válidas.

En consecuencia, el trabajo presentado a continuación busca documentar la participación de las mujeres durante la década de los 80, prestando especial atención a las prácticas políticas de las comunistas a través del análisis de entrevistas realizadas por la autora y por el Archivo Oral del Museo de la Memoria y los Derechos Humanos. En un primer apartado dialogará en torno a la producción historiográfica sobre el Partido Comunista, las mujeres y la década del 80, las fuentes orales y el género. En un segundo momento se entregarán elementos contextuales de la década, sobre las condiciones políticas, económicas y sociales del país, como también las organizaciones y espacios de participación levantados por las mujeres en el período.

Finalmente, se analizarán las trayectorias políticas y militantes de las comunistas, buscando relevar su agencia política tanto al interior del partido, como también en los espacios desde donde se articularon políticamente. ¿Cómo las comunistas se inscribieron en la irrupción de los movimientos sociales de la década del 80?, ¿desde qué lugar fueron partícipes de la sobrevivencia y resistencia en dictadura?, ¿de qué manera sus trayectorias de vida están tejidas en una historia colectiva de luchas? Son algunas de las reflexiones que cruzarán este artículo con el propósito de historizar y repensar las militancias de las comunistas en la trama narrativa de los movimientos de mujeres del período.

\section{Las fuentes, el género y la oralidad}

La escritura y los sentidos sobre el pasado reciente chileno han sido parte de disputas que aún perduran en la sociedad chilena. Desde cómo nominar al período, hasta si debiese ser un contenido a enseñar en las escuelas del país. Hoy, después del 18 de octubre de 2019, día de la revuelta política y social que inició un proceso destituyente/constituyente del país, las formas de pensar el pasado también fueron trastocadas, provocando nuevas disputas por/de las memorias y cambios en las condiciones de decibilidad y audibilidad.

A partir de la década del 2000 hasta la fecha las investigaciones sobre el pasado reciente chileno han visto un impulso prolifero. Tesis de grado y posgrado, proyectos de investigación y jornadas de historia han contribuido desde diversas aristas de análisis al campo historiográfico. 
El estudio sobre el PCCh y el papel que jugó durante la UP, la transición y en la década del 90 son parte del aporte de la academia a la historia de los/as comunistas chilenos/as.

Los estudios sobre la historia reciente del PCCh han tenido una gran contribución por las investigaciones de Rolando Álvarez. Sus aportes fundamentales se vinculan al estudio del recabarrenismo como cultura política del PCCh, como también al análisis del origen y desarrollo de la PRPM (Álvarez, 2008, 2009 y 2011) a través de un acucioso estudio de los documentos internos del partido (Álvarez, 2003 y 2008; Álvarez y Bravo, 2006).

Los estudios sobre la política militar del PCCh también fueron tributarios del desarrollo del campo de la historia reciente. Publicaciones que van desde el estudio de las discusiones a nivel de la dirección política sobre el viraje político del PCCh y que decantó en la creación de su brazo armado, el FPMR; el análisis sobre su estructura, la cultura política de su militancia durante el período, los antecedentes políticos del aparato armado, así como publicaciones sobre el estudio del órgano de difusión oficial del FPMR, El Rodriguista (Martínez, 2004; Bravo, 2017; Pérez, 2008; Rojas, 2011). Por otra parte, los trabajos sobre el papel que jugaron los comunistas en la guerrilla nicaragüense, a través del estudio de la militancia internacionalista (Álvarez y Bravo, 2006; Bonnefoy, Pérez y Spotorno, 2009; Carrera, 2010; Pérez, 2013; Olivares; 2017), también han sido significativos en los estudios sobre la política militar del PCCh.

A pesar de lo prolífico del campo de la historia reciente de las últimas décadas, las mujeres en la historiografia sobre el PCCh y su política militar, como también en una perspectiva integradora con otros movimientos sociales del período, continúa manteniéndose en los márgenes. En la historiografía no sólo es invisibilizada la participación de las mujeres, sino que se ha construido un tipo de narración que reproduce la diferencia sexual donde el valor de lo registrable se encuentra en aquellas labores y espacios masculinizados.

El "problema de la invisibilidad" de las mujeres en la historia, cómo fue categorizado por Joan Scott (1992), opera en un doble sentido en la historiografia: tanto en la invisibilización por la ausencia de fuentes históricas que hablen de las mujeres, como también en las consecuencias que tiene la propia subjetividad del historiador/a que opera al no considerar relevante la información que sí existe y que alude a los elementos sexo-genéricos del desarrollo histórico. En sus palabras, la autora alude a que "no es la falta de información sobre la mujer, sino la idea de que tal información no tenía nada que ver con los intereses de la "historia", la que condujo a la invisibilidad de las mujeres en los relatos del pasado" (p. 44). En el propio proceso de escritura es relevado el rol de los hombres en la historia y las labores masculinizadas, omitiendo 
de forma sistemática a las mujeres de los acontecimientos históricos y de los registros oficiales.

En este escenario de carencia historiográfica, la labor de pioneras investigadoras en sus tesis de pre y posgrado ha permitido explorar el estudio de las mujeres en la política armada del PCCh y en el FPMR (Lecourt, 2005; Fernández-Niño, 2009a, 2009b; Rojas, 2011; Salgado, 2014; Idini, 2005). Investigaciones donde la relectura desde el género y la construcción de fuentes orales son piedra angular de sus análisis.

Las fuentes orales son uno de los pilares en el presente artículo: sus narraciones, la forma de enunciar su pasado en un acto de rememoración y articulación de la experiencia vivida. Narración construida siempre desde el presente de enunciación y en diálogo con el/la entrevistador/a. Las entrevistas realizadas por mi autoría fueron construidas a partir de contactos entregados por los círculos más cercanos de las entrevistadas. Tener un "pase" de confianza fue fundamental para acceder a que las mujeres se sentaran a narrar sus experiencias de militancia clandestina, con toda la carga simbólica que aún existe sobre el PCCh y el FPMR. No fueron pocas quienes no accedieron a dar entrevistas, ya sea por temor a la apertura de causas judiciales o por la opción al silencio, entre otras posibles causas. Asimismo, fueron analizadas tres entrevistas realizadas por el Archivo Oral del Museo de la Memoria y los Derechos Humanos -en adelante Archivo Oral-, centro de documentación que desde su fundación ha contribuido a la construcción de fuentes orales.

Pero ¿en qué radica la decisión de tomar fuentes orales como parte fundamental del corpus de este artículo? Principalmente esta decisión se tomó por dos razones: el acceso a fuentes y la potencialidad analítica de la historia oral. Con relación a la primera, las escasas fuentes que existen sobre las mujeres comunistas durante el período, sobre todo las que estuvieron en el FPMR o en la tarea militar del PCCh, exigió un esfuerzo de triangulación y de relevamiento de documentación mayor, junto a la producción de las fuentes orales.

Por otra parte, la segunda razón radica en el hecho del objetivo de la investigación. Pues cuando el objetivo es poder documentar las subjetividades, las diferencias, la vida cotidiana y la cultura, las fuentes orales se hacen un imperativo. No es sólo en tanto posibilidad de acceso a la fuente -que, por cierto, es importante-, sino las particularidades que la oralidad nos entrega para el estudio de la historia.

En este sentido, no es menor plantear aquí que la potencialidad de la historia oral abre la posibilidad de rastrear las huellas que dejaron los hechos del pasado en las memorias de los sujetos. En cómo recuerdan, olvidan y construyen sus narrativas sobre el pasado. Las fuentes orales, construcción entre historiador/a y entrevistado/a, intenciona un tiempo y espacio en que los sujetos ponen en sentido el tiempo vivido (Portelli, 
1991, p. 5). Ordenan, clasifican y silencian mediante la participación del entrevistador/a mediante sus preguntas y acotaciones. De ahí que su entrecruce con la perspectiva de género y feminista permita fijar la mirada en aquellas huellas que dejó el desenvolvimiento histórico y no sólo advertir las "marcas heroicas" de la historia (Collin, 1996, p. 124).

\section{La crisis de los 80 y las organizaciones de mujeres}

La imposibilidad de cubrir la necesidad básica de alimentarse para miles de familias durante la dictadura se acentuó particularmente durante la década de los 80 , llegando a cifras de pobreza y seguridad alimentaria dramáticas. El correlato de la instalación de un nuevo modelo de acumulación fue la cesantía, la pobreza, el hambre y el miedo generalizado. Shock neoliberal sólo posible de realizar en un contexto dictatorial o de gobiernos autoritarios, como fue el caso de Inglaterra con Margaret Thatcher y Ronald Reagan en Estados Unidos, que comenzaron a implementar medidas en el mismo período.

El desmantelamiento del modelo de desarrollo chileno estuvo movilizado no sólo por la necesidad de reconfigurar las relaciones de producción con el fin de asegurar la acumulación y concentración del capital en una elite, sino a su vez para transformar la vida del trabajador/a, la clase. Con el objetivo de asegurar el equilibrio de las variables macroeconómicas, la dictadura y los funcionarios civiles hipotecaron los indicadores asociados a la microeconomía, donde el empleo pasó a ser una variable marginal en el diseño de las políticas públicas (Orellana, 2020; Schkolnik y Teitelboim, 1988).

Ahora bien, aquel momento bisagra que significó la década para la historia reciente chilena es posible periodizarla a partir de 1977, momento en que se comenzó a vivir un viraje hacia la institucionalización de la dictadura. Anunciado por el propio dictador en un acto el 11 de septiembre de ese año, Pinochet (1977) presentó un plan que contempló tres etapas para llegar a consolidar una democracia "autoritaria, protegida, integradora, tecnificada y de auténtica participación social" (p. 13). La primera etapa de recuperación fue iniciada en 1973 comandada por las Fuerzas Armadas y de Orden. La segunda etapa de transición se enfocó en la creación de un nuevo marco político institucional. Por último, la etapa de normalidad constitucional, donde se devolvería el poder político a la sociedad civil en el marco de una democracia autoritaria y restringida.

El plan de institucionalización se materializó en reformas y cambios: modificación del sistema tributario (1977 y 1984), a la reforma del sistema bancario (1975 y 1984), creación e implementación del Plan Laboral (1979) y un nuevo sistema de pensiones basado en la capitalización 
individual: el sistema de AFP (1981), la ley de amnistía (1978), junto a otras leyes asociadas al uso de suelo o el Programa de Erradicación de Campamentos (1979) dependiente del Ministerio del Interior, entre otros decretos-leyes sancionados en el período, junto con la Constitución de 1980.

Paralelamente el país vivió dos crisis profundas y consecutivas en medio del período de transformación y de represión radical. La crisis del petróleo de 1975, que afectó significativamente al país producto del shock neoliberal, y la crisis de la deuda vivida entre 1981 y 1984. Para 1988, según Clarisa Hardy (Hardy y Legassa, 1989), la clasificación de la pobreza arrojaba que el $10 \%$ de la población vivia en la pobreza crítica, el $25 \%$ en la indigencia y el $45 \%$ en la pobreza, situación que se profundizaba en la capital. De cada diez niños/as, cerca de la mitad padecía algún grado de desnutrición infantil, $79 \%$ de las mujeres en edad de procrear se encontraban bajos los estándares de peso mínimo durante los primeros años de los 80 (Bruey, 2018, p.73). En ambas crisis el desempleo alcanzó un 20\% y 30\% de la fuerza de trabajo (Schkolnik y Teitelboim, 1988, p. 21).

Ante la ausencia de Estado, desmantelado el aparato público -salud, educación, servicios básicos como luz y agua, y programas de seguridad social- las familias se vieron enfrentadas a asumir la sobrevivencia en un escenario donde los sindicatos y los partidos políticos estaban prohibidos, espacios de organización que hasta ese entonces canalizaban las demandas sectoriales.

A propósito de esto último, y como bien apunta Viviana Bravo (2017), la refundación neoliberal no sólo implicó la precarización de la sociedad, sino también una transformación en la sociabilidad y cultura del trabajo, en las subjetividades de la clase trabajadora: aspectos del orden de los afectos, de la dignidad trastocada por la dictadura, que pueden ser identificados en los trabajadores del Programa Especial de Empleo creado a partir de 1975, como fue el Programa de Empleo Mínimo (PEM) y Programa de Ocupación para Jefes de Hogar (POHJ).

Condiciones laborales precarias, de explotación extrema, para trabajadores que en algún momento fueron empleados textiles, obreros de la construcción, inscritos en sindicatos con una larga historia y reconocimiento. Con extensas jornadas laborales, el salario era menos de un tercio del mínimo legal, el que ya se encontraba por debajo de los ingresos para asegurar la subsistencia (Hardy y Legassa, 1989, p. 67). A modo de ejemplo, en 1984 el ingreso mínimo familiar llegó a tener la mitad del poder adquisitivo de 1974, pero con un aumento entre 1982 y 1985 de 183\% del agua y del 215\% de la electricidad (ibídem).

En este escenario las mujeres estuvieron presentes en las jornadas de protesta, en las cocinas colectivas, en las poblaciones y en las 
universidades, en los partidos en clandestinidad y en los organismos de derechos humanos. No en pocas ocasiones la interseccionalidad de las experiencias de las mujeres estuvo presente en sus prácticas políticas, las subjetividades se nutren, no son estáticas y se construyen del entrecruce de múltiples variantes, el género, la clase, la raza, entre otras. Las mujeres eran trabajadoras, madres, militantes politicas y estudiantes, también feministas y campesinas. Y la toma del espacio público durante la década tuvo rostro de mujer, ellas fueron parte del movimiento generalizado que fue corriendo los límites de la dictadura.

Las primeras agrupaciones que se levantaron fueron en defensa de la vida ante la tortura, la cárcel, los y las desaparecidas y el exilio. Así se formó en setiembre de 1973 el Comité de Ayuda a los Refugiados, el siguiente mes se creó el Comité de Cooperación para la Paz de Chile (COPACHI), antecedentes de la Vicaría de la Solidaridad, que fue uno de los espacios más importantes de la defensa de los derechos humanos durante la dictadura. Amparado por el Arzobispado de Santiago, la Vicaría fue un espacio de protección y sociabilidad para cientos de familiares que acudian por ayuda.

En 1975 fue fundada la Agrupación de Familiares de Detenidos Desaparecidos (AFDD) con participación de mujeres familiares de los diferentes partidos de izquierda perseguidos. Sin embargo, con las detenciones masivas y la desaparición de los miembros de dos direcciones del PCCh en 1976, no fue escasa la presencia de las comunistas en la organización con fuerza desde ese momento. La relación entre trayectorias políticas previas en los partidos de izquierda de sus dirigentas -en el Movimiento de Izquierda Revolucionaria (MIR), Partido Socialista (PS) o el PCCh-, fue un vínculo que repercutió en las formas de luchas de los organismos, en sus estrategias, en las tensiones internas y también en las formas de recordar.

La primera presidenta de la AFDD en 1977 fue la militante comunista Sola Sierra, quien antes del Golpe de Estado fue la encargada nacional de mujeres del Comité Central de las Juventudes Comunistas (JJCC), espacio donde organizó encuentros nacionales de mujeres militantes y simpatizantes. Trayectorias que nos hablan de la política específica hacia las mujeres desde el partido que, más allá de no adscribir al feminismo, desarrolló una política de masas reconociendo en ellas un sujeto histórico relevante en el proceso revolucionario.

En el caso de Sola Sierra, con una vasta experiencia politica, fue una de las impulsoras de una de las primeras acciones públicas y masivas de resistencia contra la dictadura: la toma del edificio de la CEPAL y una huelga de hambre durante diez dias de veinticuatro mujeres y dos hombres pertenecientes a la AFDD.

El cuerpo de las mujeres fue un medio de lucha para la denuncia, 
poner el cuerpo, su cuerpo, se transformó en una herramienta política, en las calles exigiendo justicia o encadenándose en el ex Congreso Nacional en Santiago (1979). Al interior de las filas del PCCh, en el Frente de Derechos Humanos integrado fundamentalmente por mujeres, ${ }^{2}$ ellas promovieron este tipo de estrategias politicas de carácter más insurreccional. Vilma Rojas, quien antes del golpe de Estado fue diputada por Antofagasta, perteneció al Frente de Derechos Humanos y relató cómo sus compañeros se oponían a realizar acciones públicas de esa envergadura, y cómo fueron las compañeras quienes corrieron los limites para vencer el miedo (Lecourt, 2005, p. 59; Robles, 2020).

Posteriormente se forman la Agrupación de Familiares de Ejecutados Políticos, (AFEP), la Agrupación de Familiares de Presos Políticos (AFPP), la Asamblea de Derechos Humanos, entre otros organismos de derechos humanos. En todos estos espacios las mujeres fueron las protagonistas: defendiendo la vida, exigiendo justicia y construyendo memoria (Illanes, 2012, p. 111).

En paralelo, durante el período de las organizaciones económicas populares, el trabajo reproductivo ejercido desde lo colectivo y el trabajo no remunerado comenzaron a sostener las casas de miles de chilenos/ as. En otras palabras, una economía solidaria fue lo que posibilitó a miles de familias sobrevivir y resistir a las consecuencias del shock neoliberal. Con el amparo de la iglesia católica, la población pudo levantar iniciativas populares que permitían suplir las necesidades básicas, como fue la alimentación. Cabe mencionar que en estas organizaciones la militancia comunista también participó activamente. En las ollas comunes, las brigadas de salud, los colectivos de viviendas y organización de allegados, los comedores populares y el "comprando juntos".

Asimismo, al calor de las jornadas nacionales de protesta de 1983, fue acuñada la consigna "Democracia en el país y en la casa", condensando la perspectiva feminista de la lucha contra la dictadura. Durante ese año se levantó el Movimiento Pro Emancipación de la Mujer Chilena (MEMCH 83), ${ }^{3}$ tomando el nombre y la historia de lucha de las sufragis-

2. Una de las razones de la distribución por género de las agrupaciones se encuentra en lo generizada del ejercicio represivo de la dictadura. A modo de ejemplo, según el Informe Retting del total de víctimas $94 \%$ fueron hombres y un $6 \%$ mujeres, por tanto, quienes quedaron para dar testimonio y reclamar por sus familiares, fueron fundamentalmente mujeres (Hiner, 2015, p. 257).

3. El Movimiento Pro Emancipación de la Mujer Chilena surgido en el año 1983 adoptó el nombre del MEMCh histórico activo durante los años 1935 y 1953. Fue integrado por diversas agrupaciones de mujeres con el fin de luchar contra la dictadura con las banderas del feminismo. La socióloga y politóloga Julieta Kirkwood (1936-1985), considerada una de las teóricas feminista más importante en el Chile reciente, fue una de sus fundadoras. 
tas de los 30. Mujeres por la Vida también se articuló y convocó a una gran diversidad de mujeres opositoras. Ambas agrupaciones ocuparon un lugar fundamental en la disputa del espacio público y en la toma de las calles, en la denuncia y en la acción creativa para acabar con la dictadura, especialmente durante las jornadas de protesta nacional (1983-1986). Entre sus intervenciones más importantes se encuentran el Acto en el Teatro Caupolicán de 1983, la marcha Somos Más de octubre de 1985 en denuncia de las violaciones a los derechos humanos, como también todas las conmemoraciones del 8 de marzo, entre otras manifestaciones (Valdés, 1993, p. 50).

Las mujeres en tanto trabajadoras, estudiantes, dueñas de casa o militantes políticas, con no menos tensiones entre agrupaciones y disputas con/entre los partidos de izquierda tradicionales como el comunista -imposible no mencionar en esta línea la crítica de Julieta Kirkwood hacia los partidos de izquierda y sus prácticas machistas (1986)-, fueron parte de la militancia en dictadura. Por otra parte, también la violencia que vivian muchas en sus relaciones de pareja, la violencia institucional y estructural a la que estaban enfrentadas se tradujo en que la decisión de organizarse implicara una ruptura en las relaciones sexo-genéricas dominantes. Nadie les entregó ese espacio, lo disputaron en la vida cotidiana, en los partidos, en las universidades, en las agrupaciones de trabajadores. La "democracia en el país y en la casa" fue una consigna que cruzó las vivencias de las mujeres independiente de su trinchera de lucha. Para las comunistas no fue diferente.

\section{Las comunistas y la interseccionalidad de luchas}

La trayectoria militante y la propia historia de vida de Francisca Rodríguez condensa algunas de las cuestiones planteadas anteriormente, la interrelación de las estrategias de lucha como mujer comunista. Al momento de la entrevista Francisca continuaba militando en el PCCh y se desempeñaba como directora nacional de la Asociación Nacional de Mujeres Rurales e Indígenas (ANAMURI), proveniente de una familia comunista, comenzó su trabajo partidario en las Juventudes Comunistas.

Durante el gobierno de la Unidad Popular fue parte de la Comisión Femenina de las JJCC y parte del Departamento Juvenil de la CUT. Durante los primeros años de la dictadura trabajó clandestinamente en la articulación de los organismos de derechos humanos, en el trabajo de solidaridad y de reconstrucción de las redes de apoyo, en los años más complejos en cuanto represión hacia el PCCh. Posteriormente deja la clandestinidad para incorporarse al trabajo político con su esposo en la Confederación Nacional Sindical y Campesina Ranquil, donde 
organizó en el año 1979 el Primer Encuentro de Mujeres Campesinas, donde llegaron alrededor de 300 campesinas: $^{4}$

El trabajo que había ahí no había un trabajo que estuviera dirigido específicamente a las mujeres, no, yo siempre tenía mis grandes discusiones eran con mi compañero, porque yo le decía que eran tan machistas, no, que parece que, que, que no tenian esa proyección de mirar hacia las mujeres. ${ }^{5}$

La relación entre el género, la clase y el trabajo político se cruzan, la disputa interna por legitimar las organizaciones de las mujeres, válidas y necesarias en sus propias demandas y particularidades, fue una tensión que no sólo se presentó en el mundo sindical donde comenzó a trabajar Francisca. Tal como relata en la entrevista, la militante da cuenta de cómo las mujeres las consideraban un complemento necesario para poder convocar a los campesinos a la organización. Sin embargo, ante la oportunidad de realizar encuentros nacionales, ella junto a compañeras de otros partidos politicos -como fue el socialista-, se abocaron en ahondar en las problemáticas de las mujeres, construyendo un espacio de debate y organización entre mujeres.

Luego de Ranquil pasó a ser parte de la Coordinadora Nacional Sindical, también en el frente de mujeres, apuntando a la organización de las trabajadoras. En su narración reconoce la importancia que tuvo su trabajo en clandestinidad en la comisión de solidaridad, en la planificación de la huelga de hambre de 1977 de la AFDD y su aprendizaje de la experiencia militante de Vilma Rojas. Esta acumulación de capital político, sobrellevando las tensiones internas del partido y externas con otras organizaciones, colaboraron posteriormente en las alianzas con otros movimientos sociales:

Pero la lucha callejera fue muy fuerte, no, fue, fue increíble, eh nosotras nos forjamos en la calle e hicimos una unidad muy grande para crear movimientos como "Somos Más” por ejemplo con las feministas. Porque el movimiento feminista irrumpió en esos momentos y generó sin duda una nueva cultura de mujer, nosotras tenemos que reconocer que el feminismo, te

4. El Archivo Nacional, a través del Fondo Archivos Mujeres y Género, ha documentado sobre el movimiento de mujeres de la dictadura y sobre la Comisión Nacional Sindical. Para ver más: https://www.archivonacional.gob.cl/616/w3-article-93709. html?_noredirect=1 (visto por última vez el 2 de septiembre de 2021).

5. Entrevista a Francisca Rodríguez Huerta, Archivo Oral, 22 de octubre de 2015. 
digo tan comprometido con la lucha libertaria de los pueblos, genera en el país una cultura de mujer nueva, no. ${ }^{6}$

La experiencia militante de Francisca da cuenta, precisamente, de la dificultad que existe de pensar por separado y sin interrelación la diversidad de expresiones organizativas que coexistieron durante los 80 . De alguna forma, fueron las militantes quienes tejieron una politica de alianzas amplia e insurreccional con las fuerzas opositoras, la cuestión de género era un elemento que las unía a pesar de las diferencias.

Sin embargo, al interior tenían que seguir disputando los espacios y defender su lucha en tanto trabajadoras, campesinas y militantes. Durante 1982 Francisca había pasado a formar parte de la Comisión Nacional Campesina e impulsaron un simposio ese año. En el marco de esa instancia trabajaron en la elaboración de un documento: "E1 sindicalismo para las mujeres del campo es un desafio".

Presentar ese documento fue una batalla...estuvimos como quince días discutiéndolo con las organizaciones, nos revisaban hasta la última coma "no, pero es que, es que es muy puntudo, es que hay que andar con cuidado" [...] Y el último día cuando ya estábamos listas, aprobado el documento, veníamos saliendo y él, un compañero, que falleció, dice "pero que les quede claro, esto es mientras dura la dictadura, porque después las mujeres tienen que volver a la casa a cuidar sus hijos, a preparar las mermeladitas, a hacer la comida" . O sea, esa era la mentalidad que había, lo que no sabía es que no tenía vuelta atrás esto, no. ${ }^{7}$

El reconocimiento de las disputas internas y de cómo las mujeres militantes desafiaron los límites del género con sus prácticas politicas, su experiencia y el posicionamiento politico desde su lugar como mujeres comunistas no fue algo sólo de los espacios sindicales. Es el caso de los organismos de derechos humanos, como bien relata Gracia -militante del PCCh desde niña, proveniente de una familia comunista, quien al momento de la entrevista continuaba militando en el partido-, quien luego de la detención de su hermano militante del Frente Cero, ${ }^{8}$ pasó a formar parte de la AFPP. Con la distancia existente entre el momento de la narración y los acontecimientos vividos, en el tiempo de la narrativa

6. Idem.

7. Idem.

8. El Frente Cero fue el antecedente del brazo armado del PCCh durante de 1983, el Frente Patriótico Manuel Rodríguez. 
de la entrevista, Gracia realizó una evaluación crítica sobre cómo ellas vivieron la política en dictadura:

Te puedo decir de las compañeras de los detenidos desaparecidos, de los ejecutados políticos, porque yo después estuve en ese frente, en los presos políticos. Ahí las compañeras entraban a militar, defendian a sus compañeros que estaban presos, salíamos a la calle a las marchas, se encadenaban las compañeras, miles de manifestaciones. Los compañeros salían en libertad y tenían que volver al claustro. Y entonces eso nosotras lo conversábamos con las compañeras, pero ellas no rompian esa barrera. Y producto de eso mismo, es que porque además la mujer ahí surgía y se sentía empoderada y muy presente y eran otras, eran figuras, eran consideradas para la sociedad y cuando sus compañeros salieron en libertad, volvieron al claustro, ¿y qué significó? Muchas separaciones, mucho, ya no entendían y las compañeras tenían que buscar volar, si ya habian volado una vez, era imposible que les cortaran las alas de nuevo. Ha sido una trayectoria bastante significativa. ${ }^{9}$

En el caso de las mujeres, a pesar de sus propias trayectorias militantes previas, haber sido protagonistas de la/su historia no se podía borrar simplemente con el fin de la dictadura. No fueron pocos los compañeros que no comprendieron la profundidad del cambio. La militancia de las mujeres y su protagonismo trastocaron la forma de hacer politica, tejieron rebeldias, en las calles se encontraron unas a otras luchando contra la muerte: con las feministas, las socialistas, las trabajadoras, las pobladoras.

Cabe mencionar que, durante la segunda mitad de la década del 70, especialmente a partir de 1977 el PCCh estaba viviendo un fuerte proceso de discusión interna. Producto de ese largo proceso, durante los primeros años de la década del 80, el PCCh ya había realizado el reconocimiento de todas las formas de luchas como válidas, entre ellas la armada. La PRPM se había puesto en marcha.

Mientras tanto las y los militantes comenzaron a refinar sus estrategias de propaganda armada, desde una orgánica compartimentada y de trabajo clandestino. En este contexto fue que Alicia, proveniente de una familia comunista de larga data, entró a militar a las Juventudes Comunistas (JJCC) apenas cumplió la edad para ingresar y, como en el caso de las anteriores entrevistadas, también continuaba militando cuando narró sus experiencias en la entrevista. De ese período recuerda cómo enfrentaron las crisis económicas, en un Valparaíso azotado por

9. Entrevista a Gracia, 8 de febrero de 2018. 
la pobreza, y de las que también vivió sus consecuencias cuando su padre, único sustento de la familia, fue detenido. Su madre, junto a sus cinco hermanos, sobrevivieron a través de las redes de solidaridad. La experiencia limite del hambre fue vivida en primera persona.

Alicia rememora las acciones que, como Unidades de Combate de las JJCC, realizaban en las poblaciones de Valparaíso. Ante la pregunta de cómo se vivió la crisis en los cerros de la ciudad, relató:

En las poblaciones sí. Ponte tú, en Valparaíso lo que siempre fue, lo que salvaba caleta la olla, era el pescado. El pescado era súper barato, porque los viejos salían a pescar. Ponte tú, pero el acceso a la leche, a la harina, acceso en el invierno al gas, a la parafina, nada. Entonces si nosotros abriamos, inclusive una vez me acuerdo, cerca de mi casa todavía, que casi mi papi me cacheteó, que cómo era posible. Yo vivo... en Agua Santa, por ahí bajaban todos los camiones cargados se dan toda la vuelta, bajaban todos los camiones cargados con leche, con yogures, qué se yo. Y se paraban los camiones con barricadas y a los choferes los bajábamos con pistola en mano. Abríamos la hueá y la población entraba y se robaba todo lo que había dentro de los camiones. ${ }^{10}$

Las acciones estaban destinadas a suplir las necesidades de las personas, como justicia popular se robaba para dar a quienes lo necesitaba. El PCCh continuaba vinculando su trabajo político, en este caso político militar, al trabajo de masas con las poblaciones. Por otra parte, la forma de recordar y responder la pregunta sobre la pobreza en Valparaíso es respondida con el relato de las acciones que buscaron remediar la situación, narración entrecruzada por el hacer colectivo, su desarrollo político como militante y sus propias experiencias.

Las pobladoras, sujetos politicos fundamentales en la construcción de la ciudad actual, en las tomas de terrenos y en la construcción de comunidad, también transitaron en diversos espacios: entre la clandestinidad y el trabajo comunitario. Es el caso de Ema, habitante de El Montijo, antigua toma de terreno de la actual comuna de Cerro Navia en Santiago. Su historia está mediada por su participación en la toma y por su militancia durante los 70 y en la clandestinidad.

Ema, quien no se encontraba militando al momento de entregar testimonio, recordó el proceso de formación de la olla común, de la acción colectiva entre sus vecinas para ir en ayuda a los más necesitados, para suplir las necesidades más básicas a través de la solidaridad 
y el levantamiento de economías populares. Sobre la gestión de la olla común y la represión que continuó con el Golpe de Estado, recuerda:

[Las raciones diarias eran] 270, 250 y era de lunes a viernes, sábado y domingo olvídate, el lunes llegaban todos muertos de hambre, todos porque las mamás no tenían trabajo, los maridos tampoco, no tenían para cocinar, entonces tenían que los cabros salían a pedir cualquier cuestión y llegaban el día lunes muertos de hambre, había que darles más comidita, habia que darles un fondo extra el día lunes, para poder darles más, fue duro, muy duro, yo creo que ese fue el preámbulo del Golpe Militar.

¿Por qué se... después del Golpe esta olla común no siguió funcionando después del Golpe de Estado?

No po, porque llegaron los milicos nos hicieron tirar todo, nos dieron vueltas las, nos rompieron los tarros, los tambores con aceite, mezclaron el aceite con la harina, no hicieron los fideos, los pisaban, los molieron, no sirvió para nada, entonces nada, y más encima se llevaron detenida a las que estaban de turno ese día y esas algunas hablaron, se llevaron a la otra y a la única dirigente que no se llevaron en ese momento fue a mí, yo estaba en Valparaíso en la casa de una cuñada. Soy la única persona que no se llevaron en el momento en que desarmaron toda la olla común. ${ }^{11}$

En su trabajo militante realizó diversas acciones, especialmente como enlace y como encargada de finanzas de su estructura. Si bien en la entrevista realizada por el Archivo Oral del Museo de la Memoria no ahonda en detalle sobre su labor militante, entrega algunos antecedentes que permiten visualizar la experiencia política en una de las poblaciones más pobres de Santiago y cómo era vivida la represión en los sectores populares: los allanamientos constantes, la persecución y la violencia institucionalizada como una realidad cotidiana. Asimismo, permite dar cuenta la importancia que tuvo la iglesia para la protección de los y las militantes y opositores y como espacio de comunidad en tiempos donde estaba prohibida la reunión.

Yo estuve clandestina, estuve mucho tiempo clandestina, mi hermana, con su marido, también pasaron a la clandestinidad porque estaban en la radio clandestina que tenía el Partido, entonces se llevaron a, con ella pasamos los tres a la clandestinidad y trabajé clandestinamente mucho tiempo, después me

11. Ema del Carmen Alegría Vera, Archivo Oral, 21 de noviembre de 2016. 
fui a trabajar a la iglesia, hicimos, me acuerdo, una reunión y ver todo lo que estaba pasando en la iglesia Oscar Romero y nos rodearon los milicos, olvídate. Hicimos un hoyo, era de tierra, porque era una caseta. Caseta eran no más esas iglesias, hicimos hoyo y por ahí salíamos porque los milicos no, porque por la puerta principal estaban todos esperándonos. ${ }^{12}$

La militancia en las poblaciones se vivió entre la resistencia cotidiana, la sobrevivencia y en la preparación de la barricada. El conocimiento de la población, del tejido social, permitió que las y los militantes pudieran sobreponerse al miedo, porque finalmente era la comunidad quien los / las cuidaba. Era el cura que abría las puertas de la iglesia, la monja que curaba las heridas, la vecina que abria la puerta para cobijarlos o les daba una taza de té para pasar el frío en las noches de protestas. Esas experiencias de clase y género estuvieron entretejidas en la construcción identitaria como comunistas.

Al otro lado de la barricada, en el trabajo que realizaron las mujeres en la politica militar del PCCh y que formaron parte del cuerpo del FPMR, tuvieron que afrontar una serie de dificultades asociadas al género y las formas en que se construyó la diferencia al interior de la organización. Tomar en consideración también que, en un partido con larga tradición y cultura política fundada en la vía no armada al socialismo, los desplazamientos simbólicos que comenzaron a operar en la construcción identitaria del FPMR, como parte de un proceso de valorización de lo militar por sobre lo político, impactaron también en las relaciones sociales y en la construcción de nuevas subjetividades políticas dentro del PCCh.

Tomando el uso de la categoría analítica de la división sexual del trabajo realizada por Jules Falquet (2007), los principios de separación y jerarquización del trabajo también operaron dentro de la militancia politica, especialmente en los espacios más militarizados como el FPMR. A modo de ejemplo, para comprender desde dónde se situaron las militantes y las dificultades que tuvieron que sortear, el principio de separación se aplicó de la siguiente manera: las labores asociadas al aseguramiento, logística, enlace y atención médica eran labores altamente feminizadas.

En algunas ocasiones, como se refirió anteriormente, las militantes eran ubicadas para cumplir algunas de las labores de aseguramiento con el fin de demostrar su capacidad y compromiso genuino por la lucha. En la mayoría de los casos, las militantes desempeñaron esas labores acatando las órdenes de los mandos superiores, sin dar mayor 
importancia a la división de tareas y respondiendo cabalmente con lo comandado.

Efectivamente, es posible que las mujeres en mandos medios o altos hayan sido una excepción. Pese a todo, las militantes ocuparon las labores que no fueron pensadas para ellas. Y los trabajos altamente feminizados, que sin ellos era imposible mantener a flote cualquier organización política clandestina, partido, guerrilla o guerra, los cumplieron a cabalidad. Tal es el caso de las labores de enlaces o falsificación de documentos, trabajos realizados principalmente por mujeres. Alicia luego de exiliarse en 1986, y de ser atendida por meses en un hospital traumatológico de la RDA, fue designada a un curso de formación político-militar en Cuba en la especialidad de falsificación de documentos y ejerció su oficio en el PCCh cuando era necesario regularizar la documentación de no pocos/as militantes en los primeros años de la transición política.

Es el caso de Mónica, ${ }^{13}$ antigua militante del PCCh en Rancagua y secretaria de profesión, por disposición del FPMR fue formada en la falsificación de cédulas de identidad, pasaportes y todos los documentos que eran necesarios. Y la historia de Carmen, antigua militante del PCCh y también secretaria, fue enviada a Cuba para estudiar el oficio de falsificación y fabricación de documentos en clandestinidad y fue la encargada de la documentación del FPMR en Santiago (Iturriaga y Quijada, 2012, p. 94). Los relatos de Alicia, Carmen y Mónica narran la labor silenciosa, de extrema compartimentación y soledad que significó la elaboración de la documentación para el aseguramiento de la militancia del FPMR.

En paralelo, el principio de jerarquización se presentó en la valoración de aquellas actividades y tareas de carácter operativo, propaganda armada y acciones altamente militarizadas. Si para el PCCh el trabajo de masas seguía constituyendo el punto central de la PRPM, en su brazo armado comenzó a perder relevancia. La puesta en valor de "lo militar" por sobre lo político fue creciendo, ${ }^{14}$ reconfigurando la jerarquización y valoración de las funciones dentro del FPMR.

De ahí que las tareas feminizadas fueron implícitamente menos valoradas que las labores masculinizadas. Las labores que escapaban

13. Entrevista a Mónica, Rancagua, 6 de septiembre de 2018.

14. Pamela, quien fue militante del FPMR, en su narración se refirió a los cambios que sufrió la organización: "yo siento que dentro del Frente no había una buena formación política porque si no, no se hubiesen cometido los errores que se cometieron, ahí se soslayó la parte política y se le dio mucho énfasis a los fierros, a la cosa militar, por eso es que hubo la división. Por ejemplo, cuando se sale una parte del FPMR de la estructura, nos negaban la información, o sea tú no sabías en qué lado estabas" (Iturriaga y Quijada, 2012, p. 113). 
del ideal del sujeto de la revolución: armado y dispuesto al combate, la imagen del Che Guevara combatiendo, quedaban abajo en la jerarquía. La construcción de "lo femenino" y "lo masculino" en el FPMR tuvo su correlato en el grado de responsabilidades y funciones que ejercieron diferenciadamente hombres y mujeres, así como también el peso simbólico de transgredir esas barreras invisibles.

Así como Alejandra Oberti (2015, p. 209) analizó cómo las organizaciones de la nueva izquierda produjeron tecnologías de género que delimitaron las significaciones de ser "un hombre" o "una mujer", otorgando sentidos y significaciones sociales a los géneros, el FPMR también elaboró sus propios mecanismos para significar a las y los militantes. La construcción social de la diferencia en una organización político-militar tuvo como elementos comunes el fuerte componente moral de su labor, la construcción de un ideal revolucionario que apeló a un neutral masculino y sujeto representante de una ética revolucionaria superior.

En el trabajo clandestino en Chile, el cumplimiento de las labores "feminizadas" tuvo para los militantes el peso de ser trabajos menos valorizados, incluso mal vistos por sus pares ¿Cuántos/as militantes hubo en el trabajo de exploración, documentación, propaganda, aseguramiento médico o enlaces? No se sabe con certeza y son pocos quienes han encontrado un escenario de recepción propicio para la escucha. Una realidad es que las historias que se han destacado públicamente son aquellas que han sustentado el ideal del sujeto revolucionario, el relato heroico y el valor de lo armado.

La división sexual del trabajo operó como regulación de los roles de género y cristalización de las relaciones sociales entre los sexos en ese contexto y espacio político específico: tanto para las masculinidades subalternas, como en la subestimación de las labores feminizadas y las transgresiones de las militantes en los espacios con mayor jerarquía. Sin embargo, ¿se puede pensar la guerra, las guerrillas o la lucha clandestina sin la red de aseguramiento, trabajo médico, cocina, comunicaciones, propaganda, enlaces e infiltración? No es una opción viable y aun así esas labores realizadas por mujeres son escasamente puestas en valor en la reconstrucción historiográfica (Álvarez, 2007; Bravo, 2017; Rojas, 2011), en las memorias personales y en las memorias de la propia organización. Así también el trabajo realizado por las otras mujeres comunistas, quienes demostraron en su militancia y en la gestión de lo cotidiano la importancia de las economías reproductivas, de las organizaciones populares, de la disputa de las calles y el valor que tuvieron sus trayectorias de vida y cultura política en las organizaciones que impulsaron. 


\section{Ideas finales}

Las mujeres no estuvieron en las primeras páginas de la historia que se construyó una vez terminada la dictadura. A pesar de la vasta producción académica de la época -también acto de resistencia y sublevación-, como fue la realizada por FLACSO o el Programa de Economía del Trabajo que ponían un especial énfasis en el análisis de los movimientos sociales de mujeres y en el estudio de la política desde el género, la escritura de la historia pareciera haber sido ciega ante las fuentes que mostraban la prolifera participación de las mujeres en la lucha por la democracia. Es posible que, como advirtiera el compañero de Francisca, las experiencias de las mujeres en el espacio público no se hayan mantenido en el tiempo para disputar los espacios de la democracia recuperada.

No obstante, uno de los propósitos del presente artículo fue reflexionar en torno a la participación de las comunistas en distintos frentes de lucha y cómo el género fue uno de los elementos constitutivos de su experiencia militante. Es posible que ese aspecto de sororidad, de comunidad por enfrentarse a las desigualdades sexo genéricas de la sociedad en los partidos, en la escuela, en las universidades, en los sindicatos y en la casa, posibilitara que las comunistas establecieran relaciones de cooperación y trabajo colaborativo con mujeres opositoras de diversos sectores. En este sentido, como bien plantea Scott (2001) cuando habla de la experiencia, no es posible entender un solo elemento en la construcción de las identidades. El peso de la cultura política, de la clase, del género, de las trayectorias de vidas, entran en juego al momento de afrontar la vida, la historia y reconstruir las memorias.

Asimismo, mirar las prácticas políticas de las mujeres comunistas tuvo como propósito relevar el aporte que realizaron ellas en los diversos espacios narrados, comprender la experiencia militante en ese espacio y lugar específico: la cultura política comunista desde el género. El PCCh no tuvo una política explícita hacia el trabajo de mujeres, tampoco una definición cercana al feminismo; no obstante, era considerado un espacio de disputa en cuanto a la lucha de masas. En este sentido, sería mezquino no reconocer el aporte de las comunistas a la historia de las mujeres en la política, como tampoco analizar situadamente cómo la diferencia se construyó durante la década de los 80 al interior de la vida partidaria.

Las mujeres estuvieron en cada una de las acciones relatadas y para llevar adelante las tareas asignadas tuvieron que superar las barreras invisibles del género, la desconfianza de sus superiores sólo por el hecho de ser mujeres. En muchos casos tuvieron que conciliar las labores del hogar, el cuidado de sus hijos/as y equilibrar los tiempos 
de la vida cotidiana con los de la militancia. No obstante, fue imposible que ambos espacios no se trastocaran y repercutieran en las formas de vivir la política. De ahí que se plantee que el género fue constitutivo en la construcción de la identidad militante y en la experiencia política de los sujetos.

Queda por ahondar detenidamente la interrelación que hubo entre el movimiento feminista y las militancias comunistas durante la década, cuánto se nutrieron unas de otras, o las tensiones que se develaron en la lucha por una causa mayor que fue derrotar a la dictadura. Asimismo, en las historias de la generación de hijos/as de desaparecidos/as que entraron a militar tempranamente en las filas de las Juventudes Comunistas, que acompañaron a sus madres desde muy pequeñas a los tribunales de justicia para interponer recursos de amparos, que hicieron de la Vicaría de la Solidaridad su hogar. Una cuestión es clara: las mujeres corrieron las barreras del género, vencieron el miedo, y con ello contribuyeron a derrotar la dictadura.

\section{Referencias}

Álvarez, R. (2003). Desde las sombras. Una historia de la clandestinidad comunista (1973-1980). LOM.

- (2007). La tarea de las tareas: luchar, unir, vencer. Tradición y renovación en el Partido Comunista de Chile (1965-1990). Tesis de doctorado en Historia. Universidad de Chile.

- (2008). Clandestinos 1973-1990. Entre prohibiciones públicas y resistencias privadas. En Historias de la vida privada en Chile. El Chile contemporáneo de 1925 a nuestros dias. Taurus.

- (2009). Los "hermanos Rodriguistas". La división del Frente Patriótico Manuel Rodríguez y el nacimiento de una nueva cultura política en la izquierda chilena.1975-1987. Revista Izquierdas. 2, 3, 1-9.

- (2011). Arriba los pobres del mundo. Cultura e identidad politica del Partido Comunista de Chile entre democracia y dictadura. 1965-1990. LOM.

Álvarez, R. y V. Bravo (2006). La memoria de las armas: para una historia de los combatientes internacionalistas chilenos en Nicaragua. Lucha Armada en Argentina, 5.

Bonnefoy, P., C. Pérez y Á. Spotorno (2009). Internacionalistas. Chilenos en la Revolución Popular Sandinista. Latinoamericana.

Bravo, V. (2017). Piedras, barricadas y cacerolas. Las Jornadas Nacionales de Protesta. Chile 1983-1986. Alberto Hurtado.

Bruey, A. (2018). Bread, Justice, and Liberty: Grassroots Activism and Human Rights in Pinochet's Chile. University of Wisconsin Press.

Carrera, J.M. (2010). Misión internacionalista. De una población chilena a la revolución sandinista. Editorial Latinoamericana. 
Collin, F. (1996). Historia y memoria, o la marca y la huella. En F. Birulés (comp.), El género de la memoria. Pamiela.

Falquet, J. (2007). División sexual del trabajo militante: reflexiones en base a la participación de las mujeres en el proceso revolucionario en El Salvador (1981-1992). En M.L. Femenías, Perfiles del feminismo iberoamericano, vol. 3 (pp. 93-122). Catálogos.

Fernández-Niño, C. (2009a). La muchacha comunista se incorpora a la lucha popular. La militancia femenina comunista. Una aproximación a la cultura politica del Partido Comunista de Chile, 1965-1973. Tesis de licenciatura en Historia, Universidad de Santiago de Chile.

- (2009b). "Y tú mujer junto al trabajador." La militancia femenina en el Partido Comunista de Chile. Revista Izquierdas, 3, II.

Hardy, C. (1986). Hambres + Dignidad = Ollas Comunes. Programa de Economía del Trabajo - Academia de Humanismo Cristiano.

- y Legassa, V. (1989). La ciudad escindida (los problemas nacionales y la Región Metropolitana). Programa de Economía del Trabajo - Academia de Humanismo Cristiano.

Hiner, H. (2015). ¿El "Nunca más" tiene género? Un análisis comparativo de las comisiones de la verdad en Chile y Argentina. Estudios de Sociologia, 20 (39).

Idini, M. (2005). Detrás de cada combatiente, un sujeto cotidiano: motivaciones, afectos y emociones en el Proyecto Rodriguista. Mimeo, Universidad de Chile.

Illanes, M.A. (2012). Nuestra historia violeta. Feminismo social y vidas de mujeres en el siglo XX: una revolución permanente. LOM.

Iturriaga, J. y K. Quijada (2012). Rebeldes y milicianas. Un acercamiento a las mujeres del Frente Patriótico Manuel Rodriguez, 1980-1987. Tesis de licenciatura en Historia y Ciencias Sociales. Universidad Arcis.

Lecourt, Y. (2005). Relaciones de género y liderazgo de mujeres dentro del Partido Comunista de Chile. Tesis de magister. Universidad de Chile.

Martínez, L. (2004). El Frente Patriótico Manuel Rodríguez, 1980.1987. Tesis de licenciatura en Educación, Universidad de Santiago.

Oberti, A. (2015). Las revolucionarias. Militancia, vida cotidiana y afectividad en los setenta. Edhasa.

Olivares, J. (2017). Guerrilla. Combatientes chilenos en Colombia, El Salvador y Nicaragua. Ceibo.

Orellana, V. (2020). La deuda interna de la democracia y su crisis en el estallido de octubre. Precios, salarios y deuda morosa en el Chile actual. Aletheia, 10 (20).

Pérez, C. (2008). Violencia y politica en las publicaciones clandestinas bajo Pinochet: La palabra armada en el Frente Patriótico Manuel Rodríguez. Chile, 1983-1987". Revista de Historia Social y de las Mentalidades, XII, 2, pp. 71-90.

Pérez, C. (2013). Compañeros, a las armas: combatientes chilenos en Centroamérica (1979-1989). Centro de Estudios Públicos, 129, pp. 141-164. 
Pinochet, A. (1977). Nueva institucionalidad en Chile. s/ed.

Portelli, A. (1991). Lo que hace diferente a la historia oral. En D. Schwarzstein (comp.), La historia oral, pp. 36-51. Centro Editor de América Latina.

- (2013). Sobre los usos de la memoria: memoria-monumento, memoria involuntaria, memoria perturbadora. Sociohistórica, $32,2^{\circ}$ semestre.

- (2016). Sobre la diferencia de la historia oral. En A. Portelli, Historias orales. Narración, imaginación y diálogo. UNLP-Prohistoria.

Robles, J. (2020). Las comunistas en la lucha contra la dictadura. La rebelión popular y las agrupaciones de derechos humanos. En D. D'Antonio, K. Grammático y A. Valobra (coords.), Historia de mujeres en la acción politica. De la Revolución Rusa a nuestros dias. Imago Mundi.

- y Vidaurrazaga, T. (2021). La muerte cotidiana: militancia femenina y lucha armada en Chile, el MIR y el FPMR (1970-1990). Revista de Humanidades, 43, pp. 173-210.

Rojas, L. (2011). De la rebelión popular a la sublevación imaginada. Antecedentes de la historia politica y militar del Partido Comunista de Chile y del FPMR, 1973-1990. LOM.

Salgado, A. (2014). Una pequeña revolución. Las Juventudes Comunistas ante el sexo y el matrimonio durante la Unidad Popular. En R. Álvarez, y M. Loyola (ed.), Un trébol de cuatro hojas. Las Juventudes Comunistas de Chile en el siglo XX. Ariadna - América en Movimiento.

Scott, J. (1992), El problema de la invisibilidad. En J. Scott, Género e Historia. Instituto Mora-UAM.

- (2001). La Experiencia. Revista de Estudios de Género. La Ventana. 13, pp. 42-73.

Schkolnik, M. y B. Teitelboim (1988). Pobreza y desempleo en Poblaciones. La otra cara del modelo neoliberal. Programa de Economía del Trabajo Academia de Humanismo Cristiano.

Valdés, T. (1987). Las mujeres y la dictadura militar en Chile. FLACSO, 94.

- (1993). El movimiento social de mujeres y la producción de conocimientos sobre la condición de la mujer. FLACSO. 